Volume 14, No 3 International Journal of Radiation Research, July 2016

\title{
Variation of annual effective dose from external ionizing radiation among radiation workers of Bahawalpur Institute of Nuclear Medicine and Oncology (BINO), Pakistan
}

\author{
M.A. Gadhi' ${ }^{1}{ }^{*}$, Sh. Fatmi ${ }^{1}$, M.Sh. Gadhi ${ }^{2}$, U. Mahmood ${ }^{1}$, M. Shakil3, \\ S.A. Buzdar 4
}

${ }^{1}$ Bahawalpur Institute of Nuclear Medicine and Oncology (BINO), Pakistan Atomic Energy Commission Bahawalpur, Pakistan

2Institute of Geology, University of the Punjab, Lahore, Pakistan

${ }^{3}$ Department of Physics, University of Gujrat, Pakistan

${ }^{4}$ Medical Physics Research Group, Department of Physics, the Islamia University of Bahawalpur, Pakistan

\section{- Original article}

\author{
*Corresponding author: \\ Dr. Muhammad Asghar Gadhi, \\ Fax: +92 629255331 \\ E-mail: asghargadhi@gmail.com \\ Revised: Sept. 2015 \\ Accepted: Nov. 2015 \\ Int. J. Radiat. Res., July 2016; \\ 14(3): 229-235 \\ DOI: 10.18869 /acadpub.ijrr.14.3.229
}

\begin{abstract}
Background: The aim of the study was to analyze the effective dose record of occupationally exposed radiation workers at Bahawalpur Institute of Nuclear Medicine and Oncology department. Materials and Methods: Annual effective doses of occupationally exposed workers were measured by film badge dosimetry by sending the dosimeters to Radiation Dosimetry Laboratory (RDL), Pakistan Institute of Nuclear Science and Technology (PINSTECH), Islamabad, Pakistan. 46 Radiation workers dose records were studied for a period of 14-years (2000-13). Professionally exposed radiation workers were divided into groups depending upon their professions. Results: Average effective doses of oncologists, nuclear physicians, medical physicists, radiation technologists, nurses and other supporting staff were in the range of $0.64-1.86,0.61-2.27,0.63-1.74,0.67-2.53,0.65-2.31$ and 0.68-1.79 mSv respectively. The highest annual dose received by radiation technologist was $4.95 \mathrm{mSv}$. Nobody received the radiation dose greater than $5 \mathrm{mSv}$ in any year and no overexposure case has been noticed throughout the study period. Conclusion: The results revealed that occupationally exposed individuals received doses lower than the recommended annual limits of 20 $\mathrm{mSv} \mathrm{y}^{-1}$. This study provides basis to set up action level that is obligatory by Pakistan Nuclear Regulatory Authority, Pakistan.
\end{abstract}

Keywords: Effective dose, occupational exposure, dose limits, ionizing radiation.

\section{INTRODUCTION}

The ionizing radiation sources involving $\mathrm{X}$ rays, gamma rays and beta particles, being used for cancer diagnosis and its treatment. Bahawalpur Institute of Nuclear Medicine \& Oncology (BINO), is one of the institutes working under the umbrella of Pakistan Atomic Energy Commission (PAEC). BINO has acquired its repute as an active operational unit in the field of cancer diagnosis and treatment in the region. The radiation equipment amenities entail; cobalt- 60 teletherapy unit, superficial X-rays machine, high dose rate Brachytherapy, single-photon emission computed tomography, dose calibrator, mammography, conventional Xrays, dexa unit and unsealed radioactive sources such as Technetium-99 m, Iodine131, Iodine-125.

In this study the relative distribution in effective dose intervals of annual average 
occupational radiation doses received by the health staff was observed. The dose intervals are predefined by United Nation Scientific Committee on the Effects Atomic Radiation (UNSCEAR) for each major practice involving ionizing radiations. This evaluation suggests an approximation of the average individuals risk in the occupational workforce. It also serves to establish action level for regulatory purposes.

The Basic Safety Standard (BSS) $(1,2)$ has prescribed individual monitoring employed to work in the controlled areas and who may receive significant exposure. Professionals that mainly concerned are radiation oncologists, diagnostic radiologists, medical physicists, radiographers, technicians and other supportive staff $(3,4)$. Several regulatory bodies at international and national level have provided guidelines for radiation safety and protection of both radiation staff and the public. These include International Commission for Radiation Protection (ICRP) (5), International Atomic Energy Agency (IAEA) (6) and at national level, Pakistan Nuclear Regulatory Authority (PNRA) (7). PNRA has adopted dose limits of occupational exposure for radiation workers as recommended by ICRP and IAEA $(1,8)$.

Occupational exposure of all the registered radi-ation workers is measured on routine basis for main-taining the dose record. It is an essential part of the process of monitoring the exposure of individuals to radiation and supports the overall objectives of monitoring. Records provide support for decision-making, demonstrate and facilitate regulatory compliance. 'Exposed workers' refer to all workers who are subject to individual radiation dose assessment $(9)$.

The main objective of this analysis is to determine the radiation safety and protection status of occupationally exposed staff at BINO within the past 14-years of activities and to compare the findings with dose limits stated by international safety standards $(1,8)$ and other published work. All exposed individuals received dose less than 5 $\mathrm{mSv}$ for reported period. No overexposure recorded in the analysis period (2000-13). The current investigation includes the overall status of radiation protection measures and safety of workers during the time period (2000-13). In this study, the data of 46 employees working in BINO has been analyzed for 2000-2013.

\section{MATERIALS AND METHODS}

Medical physicist has a fundamental role in the implementation of radiation protection in all radiological activities in an institute (10-12). Medical physicist (Radiation Protection Officer (RPO)) in BINO has assigned the task of personal and area monitoring to make sure the radiological safety of occupational personnel and to ensure that the limits recommended by PNRA are not surpassed. In this regard, on the whole 46 occupationally exposed workers engaged in nuclear medicine, radiation therapy and radiology at BINO has been analyzed. The radiation worker, who served for whole calendar year are included in this analysis. The details about number of occupational workers serving in the reported years are presented in results.

Film Badge Dosimetry (FBD) method presents an economical solution with the provision to maintain permanent record of doses in the form of processed films (13). A single piece of film is capable of recording radiation exposure due to beta, gamma and X-rays over a wide range of energies covering a wide doses range from $0.1 \mathrm{mSv}$ to $18 \mathrm{~Sv}$ (14). The calibration of films has been done by the Secondary Standard Dosimetry Laboratory (SSDL) on cubical polymethyl methacrylate water phantom using gamma sources (cobalt-60 and cesium-137). The evaluation of whole-body effective dose is carried out by using the dose assessment algorithm (15). RDL is responsible for providing personal dosimetry services at national level. Both the RDL and the SSDL are bound to regularly take part in inter comparison services regarding personal dosimeters planned by IAEA and IAEA (RCA) at the international and regional level. The results are in consistency with the standards and remain within the 
proclaim curves made available by the IAEA for personal dosimetry purposes (16).

Film dosimeters are used for monitoring of occupational exposure to radiation workers at BINO. Each film is assigned a unique ID, wearer's name and designation for traceability. These dosimeters are obtained from RDL, Islamabad in last week of every month. These are replaced to all radiation workers on first calendar date and used dosimeters are sent back to RDL for dose assessment. The results are maintained at RPO office since 2000 to date. In case of high dose of an individual, concerned individual and radiation safety committee at the institute are conversant thus to look into the causes of high dose and to verify its realness. If the realness is not established, the said dose is obliterated from the dose record. Each worker is instructed to wear the film badge on the upper torso. An awareness drive has been initiated in 2012. The statistical software like Microsoft Excel \& SPSS 16.0 was used for statistical data analysis. End note was used for reference management. Average annual effective dose, std. deviation were the statistical test.

\section{RESULTS}

PNRA has adopted in Pakistan the effective dose limit $\left(20 \mathrm{mSv}^{-1}\right)$ for uniform whole body exposure for occupational workers as allowed by ICRP and IAEA $(1,8)$. The average annual collective effective dose per worker was remained in the range $0.66-2.09 \mathrm{mSv}$. The distribution of the annual individual doses in the years 2000-13 and separately in 2013 is depicted in table 1.

The $17 \%, 81 \%$ and $2 \%$ of workers remained in 0-0.99, 1-2.99 and 3-4.99 mSv effective dose ranges respectively whereas when separately analyzed for 2013 , it was found that $97 \%$ and only 3\% of workers remained in 0-0.99 and 1$1.99 \mathrm{mSv}$ respectively. The analysis of the data has indicated a significant improvement in radiation protection status in the institute during 2013.

The result of annual average effective dose (AAED) is a sign of general tendency of occupational exposure in a particular type of radiation work during a year. In table 2, distributions of annual average effective doses of occupational groups are presented for investigated years. The range for oncologists, nuclear physicians, medical physicists, radiation technologists, nurses and other supportive staff are 0.64-1.86, $0.61-2.27,0.63-1.74,0.67-2.53,0.65-2.31$ and $0.68-1.79 \mathrm{mSv}$ respectively. Higher doses of radiation workers as reported by various researchers (17-22) are listed in table 3 for comparison. The results of current analysis are comparable to other researchers (17-22).

The distribution of radiation workers and their annual average doses as well as standard deviation during 2000-13 in radiation therapy, nuclear medicine and radiology are depicted in table 4.

These values for radiation therapy, nuclear medicine and radiology remain in the range $0.65-1.76,0.65-2.94$, and 0.69-2.22 $\mathrm{mSv}$ respectively.

Average dose per occupational worker in all medical facilities exhibit a decreasing trend in the reported period. This could be the result of effective implementation of radiation protection protocols (7). Table 5 shows that the average dose per occupational worker is high in nuclear medicine as compared with other departments till 2009 and then comparable for rest of the years.

In order to observe the dose distribution as per different predefined dose intervals according to UNSCEAR work sheets of occupational dose group, i.e. medical uses (23), the number of workers in radiation therapy, nuclear medicine and radiology departments and their average annual effective doses are presented in table 6 . The result shows that $18 \%$, $14 \%$ \& $21 \%$ and $82 \%, 86 \%, \& 79 \%$ of the total workers of radiation therapy, nuclear medicine and radiology are in the dose range from MDL (minimum detectable limit) to 0.99 and 1.00 to $4.99 \mathrm{mSv}$ respectively. No radiation worker's exposure falls in other dose ranges i.e. 5-9.99, 10-14.99, 15-19.9, 20-29.99, 30-50 and > $50 \mathrm{mSv}$.

Int. J. Radiat. Res., Vol. 14 No. 3, July 2016 


\section{Gadhi et al. / Variation of annual effective dose among radiation workers}

Table 1. Distribution of the annual individual doses for 2000-2013 and separately for 2013.

\begin{tabular}{|c|c|c|}
\hline Years & Dose range (mSv) & Percentage of Radiation workers (\%) \\
\hline \multirow{3}{*}{$2000-2013$} & $0-0.99$ & 16.58 \\
\cline { 2 - 3 } & $1-2.99$ & 81.55 \\
\cline { 2 - 3 } & $3-4.99$ & 1.87 \\
\hline \multirow{3}{*}{2013} & $0-0.99$ & 96.77 \\
\cline { 2 - 3 } & $1-1.99$ & 3.22 \\
\cline { 2 - 3 } & $2-4.99$ & - \\
\hline
\end{tabular}

Table 2. Distributions of annual average effective doses in mSv (AAED), Standards deviation (SD) and number of radiation workers (NOW) of occupational groups for investigated years (2000-13).

\begin{tabular}{|c|c|c|c|c|c|c|c|c|c|c|c|c|c|c|c|}
\hline Profession $_{\downarrow}$ & Years $\overrightarrow{ }$ & 2000 & 2001 & 2002 & 2003 & 2004 & 2005 & 2006 & 2007 & 2008 & 2009 & 2010 & 2011 & 2012 & 2013 \\
\hline \multirow{3}{*}{ Oncologists } & AAED & 1.68 & 1.86 & 1.28 & 1.54 & 1.29 & 1.54 & 1.43 & 1.02 & 1.16 & 1.65 & 1.35 & 1.09 & 1.50 & 0.64 \\
\hline & SD & 0.08 & 0.42 & 0.21 & 0.06 & 0.15 & 0.12 & 0.31 & 0.57 & 0.36 & 0.25 & 0.20 & 0.40 & 0.37 & 0.10 \\
\hline & No. & 3 & 3 & 3 & 2 & 4 & 4 & 3 & 2 & 4 & 5 & 5 & 6 & 5 & 5 \\
\hline \multirow{3}{*}{$\begin{array}{l}\text { Nuclear } \\
\text { Physicians }\end{array}$} & AAED & 2.23 & 1.73 & 1.60 & 2.27 & 1.86 & 1.40 & 1.34 & 1.56 & 1.14 & 1.57 & 1.64 & 0.67 & 1.37 & 0.61 \\
\hline & SD & - & - & - & - & - & 0.22 & 0.31 & 0.18 & 0.95 & 0.41 & 0.27 & 0.35 & 0.20 & 0.01 \\
\hline & No. & 1 & 1 & 1 & 1 & 1 & 2 & 3 & 2 & 4 & 3 & 3 & 4 & 3 & 2 \\
\hline \multirow{3}{*}{$\begin{array}{l}\text { Medical } \\
\text { Physicists }\end{array}$} & AAED & - & - & - & 1.10 & 1.38 & 1.30 & 1.74 & 1.6 & 1.13 & 1.67 & 1.68 & 1.06 & 1.29 & 0.63 \\
\hline & SD & - & - & - & - & - & 0.22 & 0.04 & 0.03 & 0.42 & 0.07 & 0.13 & $\begin{array}{ll}0.14 \\
\end{array}$ & 0.05 & 0.06 \\
\hline & No. & - & - & - & 1 & 1 & 2 & 2 & 2 & 3 & 3 & 3 & 3 & 3 & 3 \\
\hline \multirow{3}{*}{$\begin{array}{c}\text { Radiation } \\
\text { Technologists }\end{array}$} & AAED & 1.81 & 2.02 & 2.52 & 2.48 & 2.53 & 1.96 & 2.19 & 2.11 & 1.91 & 1.72 & 1.90 & 1.15 & 1.56 & 0.67 \\
\hline & SD & 0.39 & 1.14 & 1.29 & 1.27 & 1.17 & 1.16 & 0.71 & 0.94 & 1.09 & 0.76 & 0.38 & 0.23 & 0.37 & 0.16 \\
\hline & No. & 7 & 7 & 7 & 7 & 10 & 11 & 11 & 11 & 12 & 10 & 10 & 10 & 9 & 9 \\
\hline \multirow{3}{*}{ Nurses } & AAED & - & 1.0 & 1.78 & 2.31 & 1.63 & 1.63 & 1.77 & 1.90 & 1.25 & 1.73 & 1.84 & 1.10 & 1.39 & 0.65 \\
\hline & SD & - & 0.19 & 0.52 & 1.26 & 0.61 & 0.43 & 0.33 & 0.66 & 0.16 & 0.53 & 0.57 & 0.28 & 0.18 & 0.10 \\
\hline & No. & - & 5 & 5 & 5 & 5 & 5 & 4 & 5 & 7 & 7 & 7 & 7 & 7 & 7 \\
\hline \multirow{3}{*}{$\begin{array}{c}\text { Supporting } \\
\text { Staff }\end{array}$} & AAED & 1.53 & 1.38 & 1.54 & 1.62 & 1.04 & 1.32 & 1.74 & 1.06 & 1.14 & 1.79 & 1.49 & 1.09 & 1.36 & 0.68 \\
\hline & SD & - & 0.27 & 0.07 & 0.27 & 0.48 & 0.06 & 0.34 & 0.40 & 0.32 & 0.60 & 0.28 & 0.12 & 0.11 & 0.15 \\
\hline & No. & 1 & 5 & 4 & 4 & 5 & 2 & 4 & 4 & 5 & 6 & 6 & 6 & 4 & 4 \\
\hline
\end{tabular}

Table 3. Higher doses of radiation workers as reported by various researchers ${ }^{(17-22)}$.

\begin{tabular}{|c|c|}
\hline Study & Highest Dose (mSv) \\
\hline S. A. Memon et al. ${ }^{(17)}$ & 3.6 \\
\hline${\text { G. K. Korir et al. }{ }^{(18)}}$ al. $^{(19)}$ & 7.4 \\
\hline${\text { H. Piwowarska-Bilska } \text { et }^{(20)}}^{\text {F. Hasford et al. }}{ }^{(2)}$ & 9.5 \\
\hline K. Masood $^{(21)}$ & 9.8 \\
\hline S. A. Memon et al. (22) & 7.42 \\
\hline Current Study & 7.78 \\
\hline
\end{tabular}

Table 4. The distribution of number of radiation workers (NOW) and their annual average effective doses (AAED) in mSv as well as standards deviation (SD) during 2000-13 in radiation therapy, nuclear medicine and radiology.

\begin{tabular}{|c|c|c|c|c|c|c|c|c|c|c|c|c|c|c|c|}
\hline Department $_{\downarrow}$ & Years $\overrightarrow{ }$ & 2000 & 2001 & 2002 & 2003 & 2004 & 2005 & 2006 & 2007 & 2008 & 2009 & 2010 & 2011 & 2012 & 2013 \\
\hline \multirow{3}{*}{$\begin{array}{l}\text { Radiation } \\
\text { Therapy }\end{array}$} & AAED & 1.62 & 1.35 & 1.55 & 1.64 & 1.46 & 1.44 & 1.76 & 1.48 & 1.27 & 1.71 & 1.65 & 1.02 & 1.46 & 0.65 \\
\hline & SD & 0.19 & 0.43 & 0.4 & 0.37 & 0.81 & 0.35 & 0.35 & 0.57 & 0.21 & 0.38 & 0.44 & 0.24 & 0.26 & 0.13 \\
\hline & NOW & 5 & 13 & 12 & 12 & 15 & 15 & 15 & 15 & 17 & 18 & 18 & 19 & 16 & 16 \\
\hline \multirow{3}{*}{$\begin{array}{l}\text { Nuclear } \\
\text { Medicine }\end{array}$} & AAED & 1.91 & 2.03 & 2.48 & 2.94 & 2.38 & 2.09 & 1.98 & 2.15 & 1.62 & 1.82 & 1.7 & 1.07 & 1.47 & 0.65 \\
\hline & SD & 0.37 & 1.14 & 1.3 & 1.34 & 1.05 & 1.14 & 0.82 & 0.98 & 1.14 & 0.78 & 0.29 & 0.33 & 0.31 & 0.09 \\
\hline & NOW & 7 & 7 & 7 & 7 & 10 & 10 & 11 & 10 & 16 & 13 & 13 & 14 & 12 & 11 \\
\hline \multirow{3}{*}{ Radiology } & AAED & - & 1.59 & 2.22 & 1.52 & 1.29 & 1.32 & 1.73 & 1.57 & 1.19 & 1.58 & 1.92 & 1.27 & 1.44 & 0.69 \\
\hline & SD & - & - & - & - & - & - & - & - & 0.28 & 0.13 & 0.64 & 0.4 & 0.27 & 0.14 \\
\hline & NOW & - & 1 & 1 & 1 & 1 & 1 & 1 & 1 & 2 & 3 & 3 & 3 & 3 & 3 \\
\hline
\end{tabular}

Int. J. Radiat. Res., Vol. 14 No. 3, July 2016 
Table 5. Average annual effective dose (mSv) per occupational workers for 2000-13 for nuclear medicine, radiation therapy and radiology.

\begin{tabular}{|c|c|c|c|}
\hline \multirow{2}{*}{ Years } & \multicolumn{3}{|c|}{ Average Annual Effective Dose (mSv) } \\
\cline { 2 - 4 } & Nuclear Medicine & Radiation Therapy & Radiology \\
\hline 2000 & 1.91 & 1.62 & - \\
\hline 2001 & 2.03 & 1.35 & 1.59 \\
\hline 2002 & 2.48 & 1.55 & 2.22 \\
\hline 2003 & 2.94 & 1.64 & 1.52 \\
\hline 2004 & 2.38 & 1.46 & 1.29 \\
\hline 2005 & 2.09 & 1.44 & 1.32 \\
\hline 2006 & 1.98 & 1.76 & 1.73 \\
\hline 2007 & 2.15 & 1.48 & 1.57 \\
\hline 2008 & 1.62 & 1.27 & 1.19 \\
\hline 2009 & 1.82 & 1.71 & 1.58 \\
\hline 2010 & 1.7 & 1.65 & 1.92 \\
\hline 2011 & 1.07 & 1.02 & 1.27 \\
\hline 2012 & 1.47 & 1.46 & 1.44 \\
\hline 2013 & 0.65 & 0.65 & 0.69 \\
\hline
\end{tabular}

Table 6. Distribution of number of Radiation workers (NOW) in different effective dose intervals with their annual average effective dose (AAED) in mSv in radiation therapy, nuclear medicine and radiology during 2000-13.

\begin{tabular}{|c|c|c|c|c|c|c|c|c|c|c|c|c|}
\hline \multirow{3}{*}{ Years } & \multicolumn{4}{|c|}{ Radiation Therapy } & \multicolumn{4}{|c|}{ Nuclear Medicine } & \multicolumn{4}{|c|}{ Radiology } \\
\hline & \multicolumn{2}{|c|}{ MDL-0.99 } & \multicolumn{2}{|c|}{$4.99-1.0$} & \multicolumn{2}{|c|}{ MDL-0.99 } & \multicolumn{2}{|c|}{$4.99-1.0$} & \multicolumn{2}{|c|}{ MDL-0.99 } & \multicolumn{2}{|c|}{$4.99-1.0$} \\
\hline & NOW & AAED & NOW & AAED & NOW & AAED & NOW & AAED & NOW & AAED & NOW & AAED \\
\hline 2000 & - & - & 5 & 1.62 & - & - & 7 & 1.91 & - & - & - & - \\
\hline 2001 & 2 & 0.8 & 11 & 1.45 & - & - & 7 & 2.03 & - & - & 1 & 1.59 \\
\hline 2002 & - & - & 12 & 1.55 & - & - & 7 & 2.48 & - & - & 1 & 2.22 \\
\hline 2003 & - & - & 12 & 1.64 & - & - & 7 & 2.94 & - & - & 1 & 1.52 \\
\hline 2004 & 2 & 0.56 & 13 & 1.6 & - & - & 10 & 2.38 & - & - & 1 & 1.29 \\
\hline 2005 & 1 & 0.64 & 14 & 1.5 & - & - & 10 & 2.09 & - & - & 1 & 1.32 \\
\hline 2006 & - & - & 15 & 1.76 & - & - & 11 & 1.98 & - & - & 1 & 1.73 \\
\hline 2007 & 3 & 0.75 & 12 & 1.66 & - & - & 10 & 2.15 & & & 1 & 1.57 \\
\hline 2008 & 3 & 0.9 & 14 & 1.35 & 4 & 0.51 & 12 & 1.97 & 1 & 0.99 & 1 & 1.39 \\
\hline 2009 & - & - & 18 & 1.71 & 2 & 0.52 & 11 & 2.05 & - & - & 3 & 1.58 \\
\hline 2010 & - & - & 18 & 1.65 & - & - & 13 & 1.7 & - & - & 3 & 1.92 \\
\hline 2011 & 11 & 0.87 & 8 & 1.23 & 3 & 0.53 & 11 & 1.21 & 1 & 0.89 & 2 & 1.46 \\
\hline 2012 & - & - & 16 & 1.46 & - & - & 12 & 1.42 & - & - & 3 & 1.44 \\
\hline 2013 & 15 & 0.62 & 1 & 1.08 & 11 & 0.65 & - & - & 3 & 0.69 & - & - \\
\hline
\end{tabular}

Table 7. Comparison of average annual effective doses in Nuclear Medicine, Radiation Therapy and Radiology in present investigation with other researchers ${ }^{(14,19-21,24-26)}$.

Annual average effective dose values for nuclear medicine, radiation therapy and radiology when averaged over the investigated period were 1.88, 1.44 and $1.49 \mathrm{mSv}$ respectively. These values are comparable with other investigators $(14,19-21,24-26)$ as shown in table 7.

\begin{tabular}{|l|c|c|c|}
\hline Duthors & $\begin{array}{c}\text { Department } \\
\text { Medicine } \\
\text { (mSv) }\end{array}$ & $\begin{array}{c}\text { Radiation } \\
\text { Therapy } \\
\text { (mSv) }\end{array}$ & $\begin{array}{c}\text { Radiology } \\
\text { (mSv) }\end{array}$ \\
\hline${\text { Jabeen A et al. }{ }^{(14)}}^{\text {Piwowarska-Bilska H et al. }{ }^{(19)}}$ & 1.55 & 1.17 & 1.47 \\
\hline Hasford F et al. $^{(20)}$ & 2.47 & - & - \\
\hline Masood K et al. $^{(21)}$ & 0.63 & 0.16 & 0.76 \\
\hline Pvaluckas PK et al. $^{(24)}$ & 1.12 & 0.88 & 0.52 \\
\hline Kamenopoulou V et al. $^{(25)}$ & 1.67 & 1.48 & 1.87 \\
\hline Weizhang W et al. ${ }^{(26)}$ & 2.27 & 2 & 3.86 \\
\hline Current Study & 1.4 & 1.25 & 1.85 \\
\hline
\end{tabular}




\section{DISCUSSION}

The analysis of the data indicates a significant improvement in radiation protection status in the institute in 2013. Initially the analysis was done in 2012, but later, a comprehensive campaign was launched including a series of lectures, practical demonstrations about the concept of time, distance and shielding (TDS) (gold standards in radiation protection) and instructions on effective use of the film dosimeters. Consequently the radiation protection has been significantly improved as shown in table 1.

The maximum annual dose received by one radiation technologist working in nuclear medicine (NM) hot lab was reported $4.95 \mathrm{mSv}$ in 2004 ( $24.75 \%$ of $20 \mathrm{mSv})$. It is expected that in nuclear medicine department, during the processes of separation, solvent extraction, purification, patient work and handling of the open sources in a hot laboratory will result in raise the overall and average values of radiation exposures. The effective dose of one staff nurse $(4.50 \mathrm{mSv}, 22.50 \%$ of $20 \mathrm{mSv}$ ) was noticed as $2^{\text {nd }}$ highest effective dose received; again she was performing her duties in indoor ward and nuclear medicine hot lab dealing with high dose Iodine-131 therapy patients. However, the received dose in both cases is less than $25 \%$ of the permissible limit. Remaining most of the workers (98\%) receive the annual average effective dose less than $3 \mathrm{mSv}$. It is clear from data presented in this exploration that the average annual dose for individual workers is well below the allowed dose limit recommended by ICRP, IAEA and PNRA $(1,7,8)$. This analysis makes a point for authorities to become vigilant for the staff of nuclear medicine department. Although the doses are well below the allowed limit in this department, yet it is imperative to further strengthen the principle of As Low As Reasonably Achievable as a special case. It is the backbone of all radiation protection practices.

The values for radiation therapy, nuclear medicine and radiology were remained in the range $0.65-1.76,0.65-2.94$, and $0.69-2.22$
$\mathrm{mSv}$ respectively. Relatively higher average annual effective doses trend was seen in nuclear medicine department as compared with other departments but within the acceptable limit. According to the literature, Mosley et al., the annual effective dose of a radiation worker working in a nuclear medicine department (without PET) was about $2.0 \mathrm{mSv}$ (27), our value for nuclear medicine is relatively higher than 2 but within permissible limit. Working with the open sources during the processes of separation, solvent extraction, purification and patient work in hot lab, positioning the patient on camera and imaging process, are the main cause of more occupational exposure in comparison with radiotherapy that was done with sealed radioactive sources. In radiotherapy and radiology, the staff has to be present in the control room (shielded from treatment room) during irradiation of patient, therefore, lessening the occupational exposure values (28).

The data presented in the current study has revealed that not only the individual radiation exposures but also the compliance of radiation protection and safety practices are as per the IAEA and PNRA guidelines. The tendency over the last 14 years confirmed strong consistency with the guidelines in force. This analysis encourages the dissemination of information to occupational workers regarding their dose received that might result in further reduction in exposure.

\section{CONCLUSION}

In conclusion, the results from this study revealed that the personnel occupationally exposed to ionizing radiation have values of annual effective doses within the recommended limits. An action level is set as $20 \%$ of permissible limit to fulfill the PNRA obligation.

\section{ACKNOWLEDGMENT}

The authors gratefully acknowledge the Pakistan Atomic Energy Commission and 
Higher Education Commission Pakistan role for supporting this study.

\section{Conflict of interest: Declared None.}

\section{REFERENCES}

1. International Atomic Energy Agency (1996) Safety Standards. International basic safety standards for protection against ionizing radiation and for Safety of Radiation sources. IAEA, Vienna.

2. International Atomic Energy Agency (2006). Safety Standard for Protecting Peopele and Environment. Fundamental Safety principles No. SF-1, IAEA, Vienna.

3. Okaro AO, Ohagwu CC, Njoku J (2012). Evalution of Personnel Radiation Monitoring in Radiodiagnostic Centers in South Eastern Nigeria. African Journal of Basic \& Applied Sciences, 2(1-2):49-53.

4. Grover SB, Kammar J, Gupta A et al. (2002) Protection against radiation hazards : Regulatory bodies, safety norms, does limits and protection devices. Indian $J$ Radiol Imaging 12: 157-67.

5. International Commission on Radiological Protection (1990) Recommendations of the ICRP. ICRP Publication 60. Pergamon Press, Canada.

6. International Atomic Energy Agency/ International Labour Organization (1999) RS-G-1.1. Occupational Radiation Protection Series. Vienna.

7. Pakistan Nuclear Regulatory Authority (2004). Regulations on Radiation Protection (PAK/904).

8. International Commission on Radiation Protection (1998) Individual Monitoring for Internal Exposure of Workers: Replacement of ICRP Publication 54. ICRP Publication 78. Ann ICRP, 27:3-4.

9. Colgan PA, Currivan L, Fenton D (2008) An assessment of annual whole-body occupational radiation exposure in Ireland (1996-2005). Radiat Prot Dosimetry, 128 (1):12-20.

10. Meghzifene A, Vano E, Heron JL et al. (2010). Roles and responsibilities of medical physicists in radiation protection. European Journal of Radiology 76: 24-27.

11. Clements J (2015) MO-E-213-03: Newer Radiation Protection Requirements in Last Decade. Med Phys, 42 (6):3561-3561.

12. Seibert J (2015) MO-E-213-02: Medical Physicist Involvement in Implementing Patient Protection Standards. Med Phys, 42 (6):3561-3561.

13. Cember H (2004) Introduction to health physics, 3rd edn. Health Physics Instrumentation, McGraw-238 Hill Inc. 365-369, USA.

14. Jabeen A, Munir A, Masood M et al. (2010) Occupational exposure from external radiation used in medical practices in Pakistan by film badge dosimetry. Radiat Prot Dosimetry, 140(4): 396-401.

15. International Atomic Energy Agency (2000). Safetyeries calibration of radiation protect ion instruments. Safety Report Series No. 16.

16. International Atomic Energy Agency (1994) International basic safety standard for protection against ionizing radiation and for the safety of radiation sources. IAEA Safety Series No. 115-1.

17. Memon SA, Laghari NA, Cheema AA (2012) Evaluation of Radiation Workers' Occupational Doses Workingat NIMRA Jamshoro. JLUMHS, 11(03): 190-94.

18. Korir GK, Wambani JS, Korir IK (2011) Estimation of annual occupational effective doses from external ionising radiation at medical institutions in Kenya. $S A$ Journal of Radiology, 15(4): 116-119.

19. Piwowarska-Bilska $\mathrm{H}$, Birkenfeld $\mathrm{B}$, Listewnik $\mathrm{M}$ et al. (2010) Long-term monitoring of radiation exposure of employees in the department of nuclear medicine (SZCZECIN, POLAND) in the Years 1991-2007. Radiation Protection Dosimetry, 140(3): 304-7.

20. Hasford F, Owusu-Banahene J, Amoako JK et al. (2012) Assessment of annual whole-body occupational radiation exposure in medical practice in Ghana (20002009). Radiation Protection Dosimetry, 149(4): 431437.

21. Masood K, Ahmad M, Zafar J et al. (2012) Assessment of occupational exposure among pakistani medical staff during 2007-2011. Australas Phys Eng Sci Med, 35(3):297-300.

22. Memon SA, Qureshi ST, Laghari NA et al. (2013) Radiation workers' occupational doses: are we really careful or overconscious. world academy of science, engineering and technology. International Journal of Physical Science and Engineering, 7(8): 1039-41.

23. United nation scientific committee on the effects of atomic radiation (UNSCEAR) (2000) Occupational radiation doses. UNSCEAR Report: 20.

24. Valuckas KP, Atkočius V, Samerdokienè V (2007) Occupational exposure of medical radiation workers in Lithuania, 1991-2003. ACTA MEDICA LITUANICA, 14 (3): 155-159.

25. Kamenopoulou V, Drikos G, Dimitriou P (2000) Occupational exposure to ionising radiation in Greece (1994-1998). Radiat Prot Dosim, 91(4): 385-389.

26. Weizhang W, Wenyil Z, Ronglin C et al. (2005) Occupational exposures of Chinese medical radiation workers in 1986-2000. Radiat Prot Dosimetry, 117(4): 440-3.

27. Mosley S and Currie G (2006) Personal dosimeter use in Australian nuclear medicine practice. The Internet Journal of Nuclear Medicine, 4(1): 201-206.

28.Sutlief, SG (2015) Protection and measurement in radiation therapy. Health Physics 108 (2): 224-241. 
